The demands placed on practices mean that they may explore alternative methods of management for same day patients. However, the overall use of resources within the NHS must be considered before widespread changes are made. Nevertheless, the positive outcomes found here suggest that nurses provide a high standard of care to their patients, and this supports their extended role within primary care.

We thank the patients, nurses, and doctors who took part in this study. Professors Debbie Sharp, Nigel Stott and Richard Baker provided additional valuable support and advice.

Contributors: JC and AF initiated this study. PT, LA, and AS developed the methods. PK and EA further developed the methods and undertook data collection. CR and KP undertook the analysis. Eileen O'Donnell was responsible for data processing. All authors were involved in the interpretation of the results and writing the report. PK and CR act as guarantors for this study.

Funding: The research was supported by a grant from the Welsh Office of Research and Development for Health and Social Care. CB is supported by a fellowship from the Welsh Office of Research and Development for Health and Social Care. The Research and Development Support Unit at Southmead Hospital is supported by a grant from South West NHS Research and Development Directorate.

Competing interests: None declared.

1 Gill D, Dawes M, Sharpe M, Mayou R. GP frequent consulters: their prevalence, natural history, and contribution to rising workload. BrJ Gen Pract 1998;48:1856-7.

2 Marsh GN, Dawes ML. Establishing a minor illness nurse in a busy general practice. $B M J$ 1995;310:778-80.

3 Rees M, Kinnersley P. Nurse management of minor illness in general practice. Nursing Times 1996:92:32-3.

4 Myers P, Lenci B, Sheldon MG. A nurse practitioner as the first point of contact for urgent medical problems in a general practice setting. Fam Pract 1997;14:492-7
5 Salisbury CJ, Tettersell MJ. Comparison of the work of a nurse practitioner with that of a general practitioner. $J R$ Coll Gen Pract 1988;38:314-6.

6 Beckman H, Kaplan SH, Frankel R. Outcome based research on doctorpatient communication: A review. In: Stewart M, Roter D, eds. Communicating with medical patients. Newbury Park: Sage Publications, 1989.

7 Kinnersley P. The patient-centredness of consultations and the relationship to outcomes in primary care [MD thesis]. Bristol: University of Bristol, 1997.

8 Baker R. Development of a questionnaire to assess patients' satisfaction with consultations in general practice. Br J Gen Pract 1990;40:487-90.

9 Poulton BC. Use of the consultation satisfaction questionnaire to examine patients' satisfaction with general practitioners and community nurses: reliability, replicability and discriminant validity. $\mathrm{Br} J$ Gen Pract 1996;46:26-31.

10 Clement MJ, Kinnersley P, Howard E, Turton P, Rogers C, Parry K, et al. A randomised controlled trial of nurse practitioner versus general practitioner care for patients with acute illnesses in primary care. Cardiff: Welsh Office of Research and Development, 1999.

11 Lewis CC, Scott DE, Pantell RH, Wolf MT. Parent satisfaction with children's medical care: development, field test and validation of a questionnaire. Med Care 1988;24:209-15.

12 Bland JM, Altman DG. Statistical methods for assessing agreement between two methods of clinical measurement. Lancet 1986; $: 307-10$.

13 Office of Population Censuses and Surveys. Standard occupational classification. Vols 1-3. London: HMSO, 1991

14 Royal College of General Practitioners. Morbidity statistics from general practice: third national study 1981-2. London: RCGP, Office of Population Censuses and Surveys, 1986

15 Kinnersley P, Stott N, Peters TJ, Harvey I. The patient-centredness of consultations and outcome in primary care. Br J Gen Pract 1999;49;711-6.

16 Helman CG. Culture, health and illness. Bristol: John Wright and Sons, 1984.

17 Howie JGR, Porter AMD, Heaney DJ, Hopton JL. Long to short consultation ratio: a proxy measure of quality of care for general practice. $\mathrm{BrJ} \mathrm{Gen}$ Pract 1991:41:48-54.

18 Stewart M. Studies of health outcomes and patient-centred communication. In: Stewart M, Brown JB, Weston WW, McWhinney IR, McWilliam CL, Freeman TR, eds. Patient-centred medicine-transforming the clinical method. Thousand Oaks, CA: Sage Publications, 1995.

(Accepted 17 February 2000)

\title{
Randomised controlled trial comparing cost effectiveness of general practitioners and nurse practitioners in primary care
}

\author{
P Venning, A Durie, M Roland, C Roberts, B Leese
}

University of

Manchester Schoo

of Primary Care,

Rusholme Health

Centre, Manchester

M14 5NP

P Venning

lecturer, practice

nursing

A Durie

research associate

National Primary

Care Research and

Development

Centre, University

of Manchester,

Manchester

M13 9PL

M Roland

professor of general

practice

B Leese

senior research fellow

continued over

BMJ 2000;320:1048-53

\author{
Abstract \\ Objective To compare the cost effectiveness of \\ general practitioners and nurse practitioners as first \\ point of contact in primary care. \\ Design Multicentre randomised controlled trial \\ of patients requesting an appointment the \\ same day. \\ Setting 20 general practices in England and Wales. \\ Participants 1716 patients were eligible for \\ randomisation, of whom 1316 agreed to \\ randomisation and 1303 subsequently attended the \\ clinic. Data were available for analysis on 1292 \\ patients (651 general practitioner consultations and \\ 641 nurse practitioner consultations). \\ Main outcome measures Consultation process \\ (length of consultation, examinations, prescriptions, \\ referrals), patient satisfaction, health status, return \\ clinic visits over two weeks, and costs. \\ Results Nurse practitioner consultations were \\ significantly longer than those of the general \\ practitioners (11.57 $7.28 \mathrm{~min}$; adjusted difference
}

$4.20,95 \%$ confidence interval 2.98 to 5.41 ), and nurses carried out more tests $(8.7 \%$ v $5.6 \%$ of patients; odds ratio $1.66,95 \%$ confidence interval 1.04 to 2.66) and asked patients to return more often $(37.2 \%$ v $24.8 \% ; 1.93,1.36$ to 2.73$)$. There was no significant difference in patterns of prescribing or health status outcome for the two groups. Patients were more satisfied with nurse practitioner consultations (mean score $4.40 v 4.24$ for general practitioners; adjusted difference $0.18,0.092$ to $0.257)$. This difference remained after consultation length was controlled for. There was no significant difference in health service costs (nurse practitioner $£ 18.11 v$ general practitioner $£ 20.70$; adjusted difference $22.33,-£ 1.62$ to $£ 6.28$ ).

Conclusions The clinical care and health service costs of nurse practitioners and general practitioners were similar. If nurse practitioners were able to maintain the benefits while reducing their return consultation rate or shortening consultation times, they could be more cost effective than general practitioners. 


\section{Introduction}

Although use of nurse practitioners is well developed in the United States, it is only in the past 10 years that they have become established in the United Kingdom. A nurse practitioner has been defined as "an advanced level clinical nurse who through extra education and training is able to practice autonomously, making clinical decisions and instigating treatment decisions based on those decisions, and is fully accountable for her own practice." Models of nurse practitioner care have, however, developed in several different ways. In Britain, nurse practitioners working in general practice most commonly work as part of a team alongside general practitioners, and it is this model we have evaluated.

Nurse practitioners are increasingly used as points of first contact in primary care. The number of trained nurse practitioners is increasing as dedicated training programmes become more accessible. New government initiatives include nurses as front line providers for a national telephone advice service ${ }^{2}$ and for proposed new walk-in primary care clinics. ${ }^{3}$ Despite this, there have been few rigorous comparisons between doctors and nurses. Observational studies generally suggest that patients give positive reports of nurses in such roles. ${ }^{45}$ However, the only two randomised controlled trials comparing the cost effectiveness of nurses and doctors in first contact roles in primary care in the United States and Canada provide conflicting results. ${ }^{67}$ These studies were conducted on single sites with a small number of nurses. A recent meta-analysis commented on the limited evidence available to compare the cost effectiveness of doctors and nurses in primary care. ${ }^{8}$

The aim of this study was to compare the process, outcome, and costs of care given by general practitioners and nurse practitioners for patients requesting a same day appointment in 20 general practices. This group of patients was chosen because a high proportion would be likely to agree to randomisation as they would not have a strong preference for one practitioner who was already involved in their ongoing care.

\section{Participants and methods}

The study took place in 20 geographically dispersed practices in England and Wales. Table 1 shows the location, list size, and number of general practitioner partners in the practices recruited. Ethical approval was obtained for the 20 practices from local research ethics committees. Each practice employed a nurse who had completed a one or two year nurse practitioner training programme at diploma, BSc, or MSc level. The median length of time the nurses had been qualified as nurse practitioners was 3 (range 1-5) years and the median time as registered nurses was 22 (9-35) years. Each nurse practitioner had been seeing patients as first point of contact for at least two years.

\section{Randomisation}

In each practice, experimental sessions were booked when both the nurse practitioner and a general practitioner had appointments available for patients who asked to be seen on the same day. Patients were eligible for entry to the study if they requested an appointment the same day and were able to come to the experimental session. If these conditions were satisfied, the receptionist then asked patients whether they would agree to be randomised to see either a nurse practitioner or a general practitioner. A method of coded block randomisation was developed which meant that neither the receptionist nor the patient could determine the group to which a patient had been allocated at the time of booking. The coded blocks were generated from random number tables. The randomisation code was broken by one of the researchers at the start of each experimental session, at which point it became apparent which patient would see which practitioner. One of the researchers explained the study further to patients as they arrived for their appointment and informed consent was obtained. For drop-in clinics or where patients telephoned or called in after a session had started, the researchers randomised patients after they arrived in the surgery and had consented to enter the study. Randomisation continued until a minimum of 60 patients in each practice had been allocated to the clinician groups.

Patients were excluded from the study if one or more of the following criteria applied: patients who were temporarily resident or not yet registered with the practice, any patient with language or reading problems, any patient who was too ill, and unaccompanied children under 16 years of age.

\section{Data collection}

The general practitioners and nurse practitioners booked appointments at their normal intervals. For each consultation they recorded details of history, diagnosis, examination, tests carried out, prescriptions, and referrals. The time of each consultation, including interruptions, was recorded with an electronic time stamp. This included time taken by the nurse practitioners to get a prescription signed by a general practitioner. We extracted details of consultations in the following two weeks from the medical records.

Patients completed health status measures before the initial consultation and by post two weeks later (SF$36^{9}$ for adults or the child health questionnaire for parents of children aged 5 to $\left.16^{10}\right)$. For children under 5 years, parents completed a brief health status questionnaire which had been developed for a previous study in general practice. ${ }^{11}$ After the consultation, patients completed the medical interview satisfaction scale $\mathrm{e}^{12}$ or the paediatric version of this scale ${ }^{13}$ and the patient enablement instrument. ${ }^{14}$

We coded patients' diagnoses and prescriptions using Read codes. Data were double coded, double entered, and verified. For health status and satisfaction scales, scores were reported if $50 \%$ or more of items had been completed, and we used the method advised for the SF-36 scale to impute missing values. ${ }^{15}$ Costs of general practitioners' and nurse practitioners' time were taken from Netten et al using the actual grades on which the study nurses were employed. ${ }^{16}$ Costs of prescriptions were derived from the British National Formulary, and costs for investigations and referrals were supplied by the individual provider units associated with the practices.
Health Care Trials Unit, School of Epidemiology and Health Sciences, University of Manchester C Roberts senior lecturer

Correspondence to: P Venning, 12 Kingston Road, Didsbury,

Manchester

M20 2RZ pamelavenning@ gofree.co.uk

Table 1 Location, number of partners, and practice list size of recruited practices

\begin{tabular}{|c|c|}
\hline & $\begin{array}{l}\text { No of } \\
\text { practices } \\
(\mathrm{n}=20)\end{array}$ \\
\hline \multicolumn{2}{|c|}{ Practice location: } \\
\hline Inner city & 4 \\
\hline $\begin{array}{l}\text { Council } \\
\text { estate }\end{array}$ & 2 \\
\hline New town & 1 \\
\hline $\begin{array}{l}\text { Urban and } \\
\text { rural }\end{array}$ & 3 \\
\hline Urban & 10 \\
\hline \multicolumn{2}{|l|}{ No of partners: } \\
\hline 1 & 3 \\
\hline $2-3$ & 5 \\
\hline $4-5$ & 8 \\
\hline$>5$ & 4 \\
\hline \multicolumn{2}{|c|}{ Practice list size: } \\
\hline $3000-5000$ & 6 \\
\hline-8000 & 4 \\
\hline-10000 & 4 \\
\hline-12000 & 4 \\
\hline$>12000$ & 2 \\
\hline
\end{tabular}




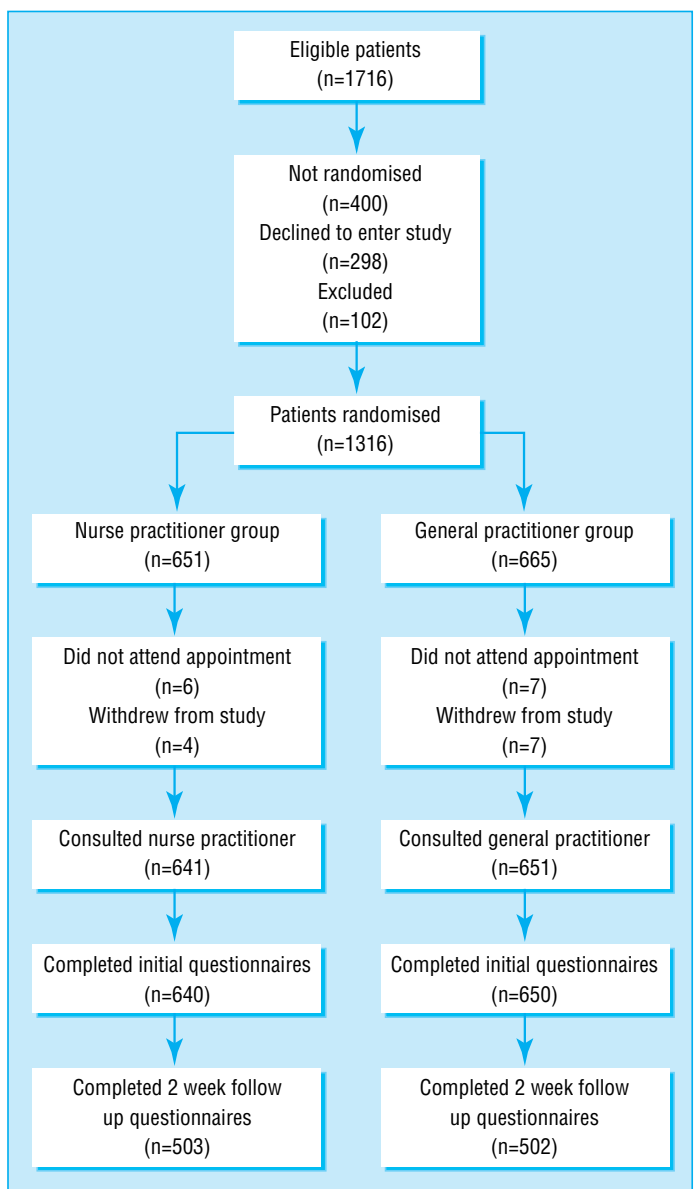

Flow chart tracking patients through study

\section{Analysis}

Because of potential correlation between the outcomes of patients treated by the same health professional, estimates of variation between health professionals may be over precise unless intracluster correlation is adjusted for. ${ }^{17}$ We adjusted outcome for the age and sex of the patients as these characteristics may also influence outcome. The statistical modelling used generalised estimating equations ${ }^{18}$ in which the intracluster correlation is modelled by an exchangeable correlation structure. A logistic regression model was used for binary outcomes. Analyses were carried out with STATA statistical

Table 2 Demographic information and the five most common diagnoses. Values are numbers (percentages) of patients

\begin{tabular}{|c|c|c|c|}
\hline & $\begin{array}{c}\text { Total } \\
(\mathrm{n}=1292)\end{array}$ & $\begin{array}{l}\text { Nurse practitioners } \\
(\mathrm{n}=641)\end{array}$ & $\begin{array}{l}\text { General practitioners } \\
\qquad(n=651)\end{array}$ \\
\hline \multicolumn{4}{|l|}{ Age (years): } \\
\hline$>16$ & $866(67.0)$ & $414(64.6)$ & $452(69.4)$ \\
\hline $5-15$ & $200(15.5)$ & $114(17.8)$ & $86(13.2)$ \\
\hline$<5$ & $224(17.3)$ & $112(17.5)$ & $112(17.2)$ \\
\hline \multicolumn{4}{|l|}{ Sex: } \\
\hline Male & $547(42)$ & $269(42)$ & $278(43)$ \\
\hline Female & $743(58)$ & $371(58)$ & $372(57)$ \\
\hline \multicolumn{4}{|l|}{ Diagnosis*: } \\
\hline Upper respiratory tract infection & $475(36.8)$ & $236(36.8)$ & $239(36.7)$ \\
\hline Viral illness & $147(11.4)$ & $81(12.6)$ & $66(10.1)$ \\
\hline No specific diagnosis & $142(11.0)$ & $76(11.9)$ & $66(10.1)$ \\
\hline Minor injuries & $119(9.2)$ & $70(11.0)$ & $49(7.5)$ \\
\hline Eye and ear conditions & $98(7.6)$ & $45(7.0)$ & $53(8.1)$ \\
\hline
\end{tabular}

software. ${ }^{19}$ As some of the cost data were highly skewed, estimates for costs were compared with estimates based on non-parametric clustered bootstrap to check the robustness of the analysis. ${ }^{20}$ Both estimates gave similar results and so only the direct estimates are presented.

\section{Results}

A total of 1716 patients were able to come to the experimental sessions and were informed about the study; 102 patients met one or more exclusion criteria and 298 declined to be randomised, leaving 1316 $(76.7 \%)$ eligible patients who were randomised. Fifteen patients subsequently did not attend the appointment which they had booked. The figure gives further details of recruitment and response rates.

Table 2 shows the demographic characteristics of the patients and the main diagnoses. Two hundred $(15.5 \%)$ patients were aged between 5 and 15, and 224 $(17.3 \%)$ were children under 5 . The commonest presenting problem was upper respiratory illness (36.8\% of all consultations).

The nurse practitioners spent a mean of 11.57 minutes face to face with patients compared with 7.28 minutes by general practitioners (table 3 ). In addition, the nurses spent a mean of 1.33 minutes per patient in getting prescriptions signed. Table 4 shows that there was no significant difference in the percentage of patients who had a physical examination (nurse practitioners $88.1 \%$ v general practitioners $85.7 \%$ ). Nurse practitioners issued fewer prescriptions than general practitioners, but the difference was not significant (391 $(61.0 \%)$ v $421(64.6 \%)$; odds ratio $0.88,95 \%$ confidence interval 0.66 to 1.17 ). Nurses ordered more tests and investigations than general practitioners (56 $(8.7 \%)$ v 37 (5.6\%); 1.66, 1.04 to 2.66). In particular, the nurse practitioners carried out more tests associated with opportunistic screening such as urine testing and cervical screening. Nurse practitioners were also significantly more likely to ask patients to return $(37.2 \%$ v $24.8 \%$; $1.93,1.36$ to 2.73$)$. In $81(12.6 \%)$ consultations the nurse discussed the patient with a doctor, and in $26(4.1 \%)$ consultations the patient was seen by the doctor.

The satisfaction questionnaires (table 5) showed patients were more satisfied after consultations with nurses. Scores were significantly higher for the adult medical interview satisfaction scale scores and all its subscales and for the paediatric medical interview satisfaction scale scores in children and two of its subscales. There were no significant differences in enablement scores between the groups. The differences in satisfaction scores were still significant when the scores were additionally controlled for the length of face to face contact (mean difference $0.16,95 \%$ confidence interval 0.08 to 0.24 ).

In the two weeks after the initial consultation, patients who had seen a nurse practitioner were more likely to make a return visit to the clinic (mean number of returns $0.49 v 0.36$ ). These return visits were mainly to general practitioners because there were more general practitioners than nurses in the practices and many of the nurses worked part time. There were no differences in health status at the end of two weeks. 
Table 3 Differences in care given at initial consultation (values adjusted for age, sex, and intracluster correlation)

\begin{tabular}{|c|c|c|c|c|c|c|c|}
\hline & \multicolumn{2}{|c|}{ Nurse practitioners } & \multicolumn{2}{|c|}{ General practitioners } & \multirow[b]{2}{*}{$\begin{array}{l}\text { Adjusted mean difference } \\
\qquad(95 \% \mathrm{CI})\end{array}$} & \multirow[b]{2}{*}{$P$ value } & \multirow[b]{2}{*}{$\begin{array}{l}\text { Intracluster } \\
\text { correlation }\end{array}$} \\
\hline & $\begin{array}{l}\text { No of } \\
\text { patients }\end{array}$ & Mean (SD) & $\begin{array}{l}\text { No of } \\
\text { patients }\end{array}$ & Mean (SD) & & & \\
\hline Total consultation time (min) & 639 & $12.90(6.28)$ & 639 & $7.49(4.75)$ & $5.46(4.16$ to 6.78$)$ & $<0.001$ & 0.19 \\
\hline Face to face consultation time ${ }^{*}(\mathrm{~min})$ & 639 & $11.57(5.79)$ & 651 & $7.28(4.80)$ & 4.20 (2.98 to 5.41$)$ & $<0.001$ & 0.17 \\
\hline $\begin{array}{l}\text { Mean number of physical } \\
\text { examinations per patient }\end{array}$ & 612 & $2.28(1.55)$ & 635 & $1.95(1.57)$ & $0.19(-0.03$ to 0.71$)$ & 0.072 & 0.19 \\
\hline Mean number of return visits & 638 & $0.49(0.79)$ & 651 & $0.36(0.66)$ & 0.14 (0.05 to 0.22$)$ & 0.002 & $0.0 \dagger$ \\
\hline
\end{tabular}

${ }^{*}$ Face to face consultation time $=$ total consultation time minus time to have prescription signed or time to sign a prescription.

†Negative estimate of intracluster correlation coefficients.

Table 4 Differences in actions taken during consultation with nurse and general practitioners (values adjusted for age, sex, and intracluster correlation)

\begin{tabular}{|c|c|c|c|c|c|c|c|}
\hline \multirow[b]{2}{*}{ Action } & \multicolumn{2}{|c|}{ Nurse practitioner } & \multicolumn{2}{|c|}{ General practitioner } & \multirow[b]{2}{*}{ Odds ratio $(95 \% \mathrm{CI})$} & \multirow[b]{2}{*}{$P$ value } & \multirow{2}{*}{$\begin{array}{l}\text { Intracluster } \\
\text { correlation }\end{array}$} \\
\hline & No of patients & $\%$ & No of patients & $\%$ & & & \\
\hline Physical examination & $590 / 640$ & 88.1 & $572 / 649$ & 92.2 & 1.76 (0.90 to 3.42$)$ & 0.097 & 0.10 \\
\hline Prescription given & $391 / 641$ & 61.0 & $421 / 651$ & 64.7 & 0.88 (0.66 to 1.17$)$ & 0.375 & 0.03 \\
\hline Antibiotic prescribed & $195 / 641$ & 30.4 & $207 / 651$ & 31.7 & 0.94 (0.76 to 1.17$)$ & 0.576 & $0.0^{*}$ \\
\hline Investigation carried out & $56 / 641$ & 8.7 & $37 / 651$ & 5.6 & 1.66 (1.04 to 2.66$)$ & 0.033 & 0.01 \\
\hline Hospital referral & $11 / 641$ & 1.7 & $25 / 651$ & 3.8 & 0.50 (0.16 to 1.63$)$ & 0.250 & 0.08 \\
\hline Asked to return & $236 / 634$ & 37.2 & $161 / 648$ & 24.8 & 1.93 (1.36 to 2.73 ) & $<0.001$ & 0.05 \\
\hline Actually returned & $224 / 634$ & 35.3 & $184 / 647$ & 28.4 & $1.42(1.18$ to 1.71$)$ & $<0.001$ & $0.0^{*}$ \\
\hline
\end{tabular}

*Negative estimate of intracluster correlation coefficient.

Table 6 shows health service costs. These include the basic salary costs of each health professional plus the costs of prescriptions, tests, referrals, and the cost of return consultations in the following two weeks. Since return consultations were not timed, we estimated that they lasted an average of 7 minutes for general practitioner consultations and 11.5 minutes for nurse practitioner consultations. There was no significant difference in the cost of care given by the nurse practitioners and the general practitioners. Further details of costings are available from us on request.

\section{Discussion}

We have evaluated care given by nurse practitioners working as part of primary care teams alongside general practitioners. Our results do not therefore relate to nurse practitioners who are working independently. It is often assumed that when nurses substitute for doctors, the same service is provided. ${ }^{21}$ However, the British literature suggests that the combi- nation of nursing and medical skills provides a more comprehensive and flexible service for patients than that provided by doctors. ${ }^{22}$ Our study provides limited support for this theory.

In many respects the behaviour of the nurses was similar to that of general practitioners, but some important differences existed. Nurse practitioners spent more time with patients and were more likely to ask patients to return. There were no differences in health outcome, although the study did not have sufficient power to detect a difference in rare serious events.

The differences in working styles between nurse practitioners and general practitioners are shown by the number and types of tests ordered and the numbers of patients who were asked to return to surgery. Nurse practitioners carried out more opportunistic screening. This was also found in a comparative study in the United States. ${ }^{7}$

In Britain only two groups of nurses (district nurses and health visitors) are able to prescribe drugs, and then from a limited list of items. During training nurse practitioners do an extensive pharmacology module

Table 5 Differences in satisfaction after consultation (adjusted for age, sex, time, and intracluster correlation)

\begin{tabular}{|c|c|c|c|c|c|c|c|}
\hline & \multicolumn{2}{|c|}{ Nurse practitioner } & \multicolumn{2}{|c|}{ General practitioner } & \multirow[b]{2}{*}{$\begin{array}{l}\text { Adjusted mean difference } \\
\qquad(95 \% \mathrm{Cl})\end{array}$} & \multirow[b]{2}{*}{$P$ value } & \multirow[b]{2}{*}{$\begin{array}{l}\text { Intracluster } \\
\text { correlation }\end{array}$} \\
\hline & $\begin{array}{l}\text { Mean (SD) } \\
\text { score }\end{array}$ & $\begin{array}{c}\text { No of } \\
\text { patients }\end{array}$ & $\begin{array}{l}\text { Mean (SD) } \\
\text { score }\end{array}$ & $\begin{array}{c}\text { No of } \\
\text { patients }\end{array}$ & & & \\
\hline \multicolumn{8}{|l|}{ Adults } \\
\hline Medical interview satisfaction scale & $4.40(0.46)$ & 388 & $4.24(0.52)$ & 390 & 0.18 (0.09 to 0.26$)$ & $<0.001$ & 0.04 \\
\hline Communication & $4.35(0.54)$ & 370 & $4.21(0.60)$ & 384 & $0.13(0.06$ to 0.21$)$ & 0.001 & $0.0^{*}$ \\
\hline Distress relief & $4.43(0.47)$ & 390 & $4.26(0.57)$ & 400 & $0.19(0.08$ to 0.29$)$ & 0.001 & 0.01 \\
\hline Clinician behaviour & $4.44(0.49)$ & 375 & $4.22(0.57)$ & 369 & $0.23(0.15$ to 0.32$)$ & $<0.001$ & 0.2 \\
\hline Enablement score & $4.92(3.62)$ & 335 & $4.43(3.65)$ & 361 & $0.65(-1.50$ to 0.19$)$ & 0.13 & 0.14 \\
\hline \multicolumn{8}{|l|}{ Children } \\
\hline Medical interview satisfaction scale† & $4.39(0.46)$ & 220 & $4.17(0.57)$ & 181 & $0.23(0.12$ to 0.34$)$ & $<0.001$ & 0.3 \\
\hline Communication with parent & $4.58(0.51)$ & 223 & $4.48(0.65)$ & 190 & $0.07(-0.26$ to 0.16$)$ & 0.159 & 0.00 \\
\hline Communication with child & $4.16(0.63)$ & 176 & $3.67(0.77)$ & 147 & 0.47 (0.29 to 0.67$)$ & $<0.001$ & 0.11 \\
\hline Distress relief & $4.41(0.53)$ & 222 & $4.21(0.64)$ & 186 & 0.21 (0.08 to 0.34$)$ & 0.002 & 0.04 \\
\hline Adherence intent & $4.47(0.53)$ & 218 & $4.44(0.53)$ & 185 & $-0.01(-0.10$ to 0.08$)$ & 0.817 & $0.0^{*}$ \\
\hline
\end{tabular}

${ }^{*}$ Negative estimate of intracluster correlation coefficient.

†Paediatric version. 
Table 6 Difference in cost of consultation with nurse and general practitioners based on salary costs. Data are adjusted for age, sex, and intracluster correlation

\begin{tabular}{|c|c|c|c|c|c|c|c|}
\hline & \multicolumn{2}{|c|}{ Nurse practitioner } & \multicolumn{2}{|c|}{ General practitioner } & \multirow{2}{*}{$\begin{array}{c}\text { Adjusted mean } \\
\text { difference }(95 \% \mathrm{CI})\end{array}$} & \multirow[b]{2}{*}{$P$ value } & \multirow{2}{*}{$\begin{array}{l}\text { Intracluster } \\
\text { correlation }\end{array}$} \\
\hline & Mean (SD) cost (£) & Range & Mean (SD) cost (£) & Range & & & \\
\hline \multicolumn{8}{|l|}{ Initial consultation: } \\
\hline Total time & $11.71(25.23)$ & $0.66-297.1$ & $14.14(29.62)$ & $0.78-246.5$ & $2.17(-1.18$ to 5.51$)$ & 0.204 & 0.009 \\
\hline Face to face time ${ }^{\star}$ & $11.29(25.18)$ & $0.66-297.1$ & $14.11(29.63)$ & $0.79-246.5$ & $2.58(-0.73$ to 5.89$)$ & 0.127 & 0.009 \\
\hline Return consultation & $6.40(21.20)$ & $0.0-219.3$ & $6.56(22.85)$ & $0.0-217.3$ & $-0.03(-2.25$ to 2.20$)$ & 0.98 & 0.008 \\
\hline \multicolumn{8}{|l|}{ Total costs: } \\
\hline Total time & $18.11(33.43)$ & $0.66-2971$ & $20.70(33.43)$ & $0.78-300.6$ & $2.33(-1.62$ to 6.28$)$ & 0.247 & $0.0 \dagger$ \\
\hline Face to face time* & $17.69(33.41)$ & $0.66-297.1$ & $20.68(33.41)$ & $0.78-300.6$ & $2.73(-1.20$ to 6.66$)$ & 0.173 & $0.0 \dagger$ \\
\hline
\end{tabular}

${ }^{*}$ Face to face time $=$ total consultation time minus time to get a prescription signed or time to sign a prescription.

†Negative estimate of intracluster correlation coefficient.

with supporting modules in pathophysiology and disease management, and they argue that they are able to use the same range of drugs as doctors. ${ }^{23}$ We found that the nurse practitioners had similar prescribing behaviour to the general practitioners. As they had been qualified for some time, unlike nurse practitioners in other British studies, ${ }^{42}{ }^{24}$ and were experienced nurses, this finding is not unexpected. These nurses were working in teams alongside general practitioners and consistent prescribing behaviour should, in theory, be adopted by all practice staff. Indeed, some practices had developed specific prescribing protocols for both general practitioners and nurse practitioners.

Patient satisfaction is an important component of nearly all studies looking at the role of nurse practitioners, and patients generally report high levels of satisfaction with nurse practitioner care. ${ }^{45222425}$ Increased satisfaction has been linked with longer consultations, and nurse practitioners have been shown to spend longer with patients than general practitioners. However, the differences in satisfaction remained in our study after we had controlled for differences in consultation time.

The health service costs of consultation with nurse practitioners were $12.5 \%$ lower than those for general practitioners, but this difference was not significant. However, a larger study with greater power to detect cost differences is needed. We were unable to do power calculations for cost before the study because none of the British studies of nurse practitioners have compared cost of consultations for general practitioners and nurse practitioners. ${ }^{4522}{ }^{24}$ In the United States studies have shown conflicting results. ${ }^{25}$ Nurses were paid less than the general practitioners, but they took longer to see patients and more of their patients returned for further consultations. This reduced the overall difference in consultation costs. If lifetime training costs were included the general practitioner costs would be higher.

\section{Conclusion}

Our results relate to patients requesting a same day appointment in general practice and cannot necessarily be generalised to other situations. Overall, the clinical care and outcome were similar for nurse practitioners and general practitioners. Patients who requested a same day appointment were satisfied with nurse practitioner consultations. If nurse practitioners were able to work in different ways-for example, to shorten their consultation times (which our results suggest will not alter higher patient satisfaction with

\section{What is already known on this topic}

Nurse practitioners are increasingly used as point of first contact in primary care

Observational studies suggest patients react positively to use of nurse practitioners

\section{What this study adds}

Patients were more satisfied with nurse practitioner consultations even after their longer consultation times were allowed for

There were few differences in clinical care and no difference in clinical outcome between nurse practitioners and general practitioners

Health service costs were not significantly different between nurses and general practitioners

nurse practitioners) or reduce their return consultation rate-they could be more cost effective than general practitioners for this group of patients.

We thank all the patients who participated in the study and the administrative, nursing, and medical staff in the 20 practices recruited for the study.

Contributors: PV had the idea for the research. PV, MR, CR, and BL obtained funding from the Wellcome Trust, PV being the principal investigator. PV and MR developed the project protocol with important input from $\mathrm{AD}$ and advice from CR and BL. Data collection, database development, and initial analysis were carried out by $\mathrm{AD}$ with help from $\mathrm{PV}$ and advice from MR, CR, and BL. Statistical modelling was carried out by CR. This paper was instigated by MR, and completed by PV with contributions from $\mathrm{CR}$ and advice from $\mathrm{AD}$ and $\mathrm{BL}$. PV and MR are guarantors.

Funding: Wellcome Trust, project number 045384.

Competing interests: None declared.

1 Royal College of Nursing. Nurse practitioners in primary health care-role definition. London: RCN, 1989.

2 Department of Health. New opportunities for NHS Direct. London: DoH, 1999. (Press release 1999/0227.)

3 Department of Health. Up to £30 million to develop 20 NHS fast access walk-in centres. London: DoH, 1999. (Press release 1999/0226.)

4 South Thames Regional Health Authority. Evaluation of nurse practitioner pilot projects: summary report. London: Touche Roche Management Consultants, STRATA, 1994.

5 University of Newcastle Upon Tyne, Centre for Health Services Research. Evaluation of nurse practitioners in general practice in Northumberland: the EROS projects 1 and 2. Newcastle Upon Tyne: CHSR, 1998.

6 Spitzer WO, Sackett DL, Sibley JC, Roberts RS, Gent M, Kergin DJ, et al. The Burlington randomised controlled trial of the nurse practitioner. $N$ Engl J Med 1974;290:251-6.

7 Diers D, Hamman A, Molde S. Complexity of ambulatory care: nurse practitioner and physician caseloads. Nurs Res 1986;35:310-4.

8 Brown SA, Grimes D. A meta-analysis of nurse practitioners and nurse midwives in primary care. Nurs Res 1995;44:332-8. 
9 Brazier JE, Harper R, Jones N, O'Cathain A, Thomas K, Usherwood T, et al. Validating the SF-36 health survey questionnaire: new outcome measure for primary care. BMJ 1992;305:160-4.

10 Landgraf J, Maunsell E, Speechley KN, Bullinger M, Campbell S, Ware J. Canadian, French, German and UK versions of the child health questionnaire: methodology and preliminary item scaling results. Qua Life Res 1998;7:433-45.

11 McKinley RK, Cragg DK, Hastings AM, French DP, Manku-Scott TK, Campbell S, et al. Comparison of out of hours care provided by patients own general practitioners and commercial deputising services: randomised controlled trial. 2. Outcome of care. BMJ 1997;314:190-3.

12 Wolf MH, Putnam SM, James SA, Stiles WB. The medical interview satisfaction scale: development of a scale to measure patient perceptions of physician behaviour. J Behav Med 1978;1:391-401.

13 Lewis C, Scott D, Pantell R, Wolf M. Patient satisfaction with children' medical care: development, field test and validation of a questionnaire. Med Care 1986;24:209-15.

14 Howie JGR, Heaney D, Maxwell M, Walker JJ. A comparison of the patient enablement instrument (PEI) against two established satisfaction scales as an outcome measure of primary care consultations. Fam Pract 1998;15:165-71.

15 Ware J. SF-36 health survey:manual and interpretation guide. Boston: Health Institute, New England Medical Center, 1993.

16 Netten A, Knight J, Dennett J, Cooley R, Slight A. A ready reckoner for staff costs in the NHS. Volume 1. Estimated unit costs. Canterbury: Personal Social Services Research Unit, University of Kent, 1998.
17 Roberts C. The implication of variation in outcome between health professionals for the design and analysis of randomised controlled trials. Stat Med (in press).

18 Zeger SL, Liang KY, Longitudinal data analysis for discrete and continuous outcomes. Biometrics 1986;42:121-30.

19 Stata Corporation. Stata statistical software, release 5.0. College Station, TX Stata Corporation, 1997.

20 Barber JA, Thompson SG. Analysis and interpretation of cost data in randomised controlled trials: review of published studies. BMJ $1998 \cdot 317: 1195-200$

21 Richardson G, Maynard A. Fewer doctors? More nurses? A review of the knowledge base of doctor-nurse substitution. York: Centre for Health Economics, University of York, 1995.

22 NHS Executive. Nurse practitioner evaluation project: final report. Uxbridge. Coopers and Lybrand, 1996.

23 Mayes M. A study of prescribing patterns in the community. Nursing Standard 1996;10(29):34-7.

24 Reveley $\mathrm{S}$. The role of the triage nurse practitioner in general medica practice: an analysis of the role. J Advan Nurs 1998;28:584-91.

25 Office of Technology Assessment. Nurse practitioners, physician assistant. and certified midwives: a policy analysis. Washington DC: US Governmen Printing Office, 1986. (Health technology case study 37, OTA-HCS-37.)

(Accepted 11 November 1999)

\title{
Cost analysis of nurse telephone consultation in out of hours primary care: evidence from a randomised controlled trial
}

\author{
Val Lattimer, Franco Sassi, Steve George, Michael Moore, Joanne Turnbull, Mark Mullee, \\ Helen Smith
}

\begin{abstract}
Objective To undertake an economic evaluation of nurse telephone consultation using decision support software in comparison with usual general practice care provided by a general practice cooperative.

Design Cost analysis from an NHS perspective using stochastic data from a randomised controlled trial. Setting General practice cooperative with 55 general practitioners serving 97000 registered patients in Wiltshire, England.

Subjects All patients contacting the service, or about whom the service was contacted during the trial year (January 1997 to January 1998).

Main outcome measures Costs and savings to the NHS during the trial year.

Results The cost of providing nurse telephone consultation was $£ 81237$ per annum. This, however, determined a $£ 94422$ reduction of other costs for the NHS arising from reduced emergency admissions to hospital. Using point estimates for savings, the cost analysis, combined with the analysis of outcomes, showed a dominance situation for the intervention over general practice cooperative care alone. If a larger improvement in outcomes is assumed (upper 95\% confidence limit) NHS savings increase to $£ 123824$ per annum. Savings of only $£ 3728$ would, however, arise in a scenario where lower $95 \%$ confidence limits for outcome differences were observed. To break even, the intervention would have needed to save 138 emergency hospital admissions per year, around $90 \%$ of the effect achieved in the trial. Additional savings of £16 928 for general practice arose from reduced travel to visit patients at home and fewer surgery appointments within three days of a call.
\end{abstract}

Conclusions Nurse telephone consultation in out of hours primary care may reduce NHS costs in the long term by reducing demand for emergency admission to hospital. General practitioners currently bear most of the cost of nurse telephone consultation and benefit least from the savings associated with it. This indicates that the service produces benefits in terms of service quality, which are beyond the reach of this cost analysis.

\section{Introduction}

Nurse telephone consultation refers to an intervention in which experienced and specially trained nurses use decision support software to receive, assess, and manage calls from patients or their carers. ${ }^{1}$ The concept was tested in a UK primary care setting in $1996,{ }^{2}$ and over $30 \%$ of general practice cooperatives now employ nurse advisers. ${ }^{3}$ The safety and effectiveness of out of hours general practice care augmented by nurse telephone consultation has been shown in a randomised controlled trial. ${ }^{4}$ This trial found a substantial reduction in general practitioner workload during intervention periods, nurses managing $50 \%$ of calls without referral to a general practitioner, without any increase in the number of deaths observed within seven days of a call. Although our original hypothesis was that calls handled by the nurse alone would primarily replace calls for which the general practitioner would have delivered advice by telephone, the intervention was also associated with a reduction in the number of home visits by general practitioners, patients attending an out of hours surgery, and emergency hospital admissions. We examine the economic implications of these findings.

\section{Health Care Research Unit, University of Southampton, Southampton General Hospital, Southampton SO16 6YD \\ Val Lattimer Medical Research Council fellow Steve George director \\ Mark Mullee senior research fellow in medical statistics Joanne Turnbull research assistant continued over}

BMJ 2000;320:1053-7

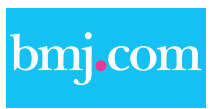

Full details of the methodology can be found on the $B M J$ 's website 